\title{
Plastic deformation of submicron-sized crystals studied by in-situ Kikuchi diffraction and dislocation imaging
}

Zhang, Xiaodan; Godfrey, Andy; Winther, Grethe; Hansen, Niels; Huang, Xiaoxu

Published in:

Nanomechanical Testing Workshop and Hysitron User Meeting

Publication date:

2012

Document Version

Publisher's PDF, also known as Version of record

Link back to DTU Orbit

Citation (APA):

Zhang, X., Godfrey, A., Winther, G., Hansen, N., \& Huang, X. (2012). Plastic deformation of submicron-sized crystals studied by in-situ Kikuchi diffraction and dislocation imaging. In Nanomechanical Testing Workshop and Hysitron User Meeting

\section{General rights}

Copyright and moral rights for the publications made accessible in the public portal are retained by the authors and/or other copyright owners and it is a condition of accessing publications that users recognise and abide by the legal requirements associated with these rights.

- Users may download and print one copy of any publication from the public portal for the purpose of private study or research.

- You may not further distribute the material or use it for any profit-making activity or commercial gain

- You may freely distribute the URL identifying the publication in the public portal 


\title{
PROGRAM
}

\author{
Nanobrücken III \\ Nanomechanical Testing Workshop \\ and \\ Hysitron User Meeting
}

March 22-23, 2012

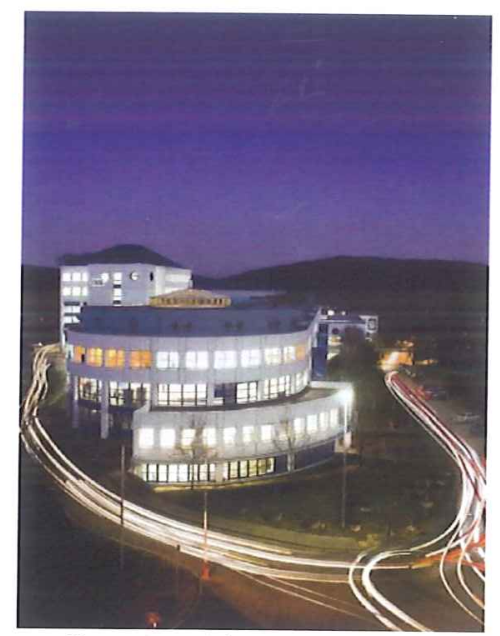

Photo Copyright: Uwe Bellhäuser

INM Saarbrücken, Germany

Program Committee

Prof. Eduard Arzt, INM Saarbrücken, Germany

Prof. Roland Bennewitz, INM Saarbrücken, Germany

Prof. Lars Hultman, Linköping University, Sweden

Dr. Andreas Schneider, INM Saarbrücken, Germany

Dr. Oden Warren, Hysitron, Inc., USA

\section{Keynote Speaker}

Prof. Jeff De Hosson, University of Groningen, The Netherlands

\section{Invited Speakers}

Prof. Daniel Kiener, University of Leoben, Austria Prof. Oliver Kraft, Karlsruhe Institute of Technology, Germany

Dr. Marc Legros, CEMES-CNRS, France

Dr. Johann Michler, EMPA, Switzerland 
PILLAR COMPRESSION SESSION

1:00-1:30

\section{*Invited Talk: "Pushing and pulling in the TEM: What can be learned from quantitative nanoscale in-situ experiments"}

\section{Kiener*}

Department Materials Physics, Montanuniversität Leoben, Jahnstraße 12, 8700 Leoben, Austria

\section{* daniel.kiener@unileoben.ac.at}

The uncommon size dependent mechanical properties of limited volumes, where smaller turns out to be stronger once the dimensions reach the micron and sub-micron range were uncovered few years ago. The general scaling trends are established and the stochastic effects typically ascribed to the behavior of few dislocations in such confined volumes. However, there is an ongoing debate what the governing dislocation mechanisms responsible for the strengthening etc. are, and what the role of the crystal structure is.

In-situ TEM techniques are ideally suited to answer such questions, as they provide the resolution to directly observe individual dislocations during a mechanical experiment within a sub-micron specimen. We used a commercial nanoindentation holder (Hysitron Picoindenter PI-95) equipped with custom diamond tips suited for sample compression and pulling. During the compression or tensile tests, the sample deformation is monitored and recorded in-situ, allowing a direct correlation between the dislocation mechanisms observed to govern yielding, hardening or failure and the measured stress-strain data.

Specimens ranging from several tens of nanometers to $\sim 500 \mathrm{~nm}$ were typically fabricated using a focused ion beam (FIB) from FCC and BCC single crystals. Since it is well known that this technique changes the material microstructure in the near surface area, several techniques were applied on the one hand to remove the FIB effects, and on the other hand to modify the sample microstructure in a controlled manner. This allows to test the properties of sub-micron volumes with microstructures ranging from deliberately damaged materials to pristine crystals.

The dislocation mechanisms observed in these experiments are discussed with respect to existing models, complementary $\mu$-Laue experiments and discrete dislocation simulations.

\section{1:30-1:50}

\section{"Plastic deformation of submicron-sized crystals studied by in-situ Kikuchi diffraction and dislocation imaging"}

Xiaodan Zhang ${ }^{1, *}$, Andy Godfrey ${ }^{2}$, Grethe Winther ${ }^{1}$, Niels Hansen ${ }^{1}$, and Xiaoxu Huang ${ }^{1}$

${ }^{1}$ Danish-Chinese Center for Nanometals, Materials Research Division, Risø National Laboratory for Sustainable Energy, Technical University of Denmark, DK-4000 Roskilde, Denmark

${ }^{2}$ Laboratory of Advanced Materials, Dept. Material Science and Engineering, Tsinghua University, Beijing 100084, P.R. China

*xzha@dtu.dk

The plastic deformation of submicron-size copper single crystals in the form of pillars has been 
characterized during in-situ compression in the transmission electron microscope up to strains of 28$33 \%$ using a state-of-the-art holder (PI-95 Picolndenter). The dimensions of the crystals used were approx. $500 \times 250 \times 200 \mathrm{~nm}^{3}$ with the compression axis oriented $1.6^{\circ}$ from [110]. Local crystallographic orientations have been determined with high accuracy using a Kikuchi diffraction method and glide of dislocations over a pillar has also been observed directly by dark field imaging. The variation in the local orientation during deformation has been followed by in-situ convergent beam electron Kikuchi diffraction (CBEKD). The in-situ observations have been followed up by post-deformation measurements with the samples still mounted in the electron microscope. Crystal breakup following localized deformation was observed in two of three crystals examined, and for all crystals the direction of rotation during deformation is in agreement with slip taking place on a subset of the four slip systems with the highest Schmid factors on the (111) and (-1-11) slip planes. A diffractionbased Burgers vector analysis confirms that the active dislocations are from slip systems with the highest Schmid factors. These results from testing of micropillars are in good agreement with the deformation behaviour previously reported for both single- and poly-crystal samples with dimensions in the millimetre range.

\section{1:50-2:10 "Compression testing of miniaturized copper bicrystals with twin- and large angle grain boundaries"}

Peter Julian Imrich ${ }^{1, *}$, Christoph Kirchlechner ${ }^{2}$, Xianghai An ${ }^{3}$, Zhefeng Zhang ${ }^{3}$, and Gerhard Dehm ${ }^{1,2}$

${ }^{1}$ Erich Schmid Institute of Materials Science, Austrian Academy of Sciences, Leoben, Austria

${ }^{2}$ Department Materials Physics, University of Leoben, Austria

${ }^{3}$ Shenyang National Laboratory for Materials Science, Institute of Metal Research, Chinese Academy of Sciences

* peter.imrich@stud.unileoben.ac.at

It has been known for a long time, that decreasing the grain size of a metal leads to a higher strength. This increase which is called the Hall Petch effect can easily be described in macroscopic dimensions although the real interactions between dislocations and boundaries stay unknown. Miniaturized tests that have been developed in the last decade and have been used to study the mechanical size effects in materials offer great possibilities to investigate dislocation boundary interactions by testing microscopic samples that are comprised of two grains only.

Here we show the deformation behavior of single crystalline and bicrystalline copper compression samples in the low micrometer region. Bicrystalline samples including a coherent twin boundary (CTB) or a large angle grain boundary (LAGB) have been deformed while recording force displacement data. The CTB-pillars surprisingly show neither strengthening, nor hardening and exhibit a very characteristic shape after deformation. Each grain has characteristic slip planes that perfectly coincide at the grain boundary. The LAGB-pillars show a very different behavior with strengthening and hardening of the sample compared to the single crystalline pillars and a bent pillar shape after deformation. The stress-strain data and sample morphology are related to possible dislocation boundary interactions. 